\title{
A educação, a solidariedade e a fraternidade como garantia de inclusão das pessoas com deficiência no mercado de trabalho dos países do Mercosul d
}

\section{La educación, la solidaridad y la fraternidad como garantía de inclusión de las personas con discapacidad en el mercado de trabajo de los países del Mercosur}

\author{
Claudio José Amaral Bahia \\ Doutor em Direito do Estado (PUC-SP) \\ Instituição Toledo de Ensino (ITE) \\ Bauru, São Paulo, Brasil \\ E-mail: claudio_amaralbahia@hotmail.com
}

\author{
Manuella de Oliveira Soares \\ Doutora em Sist. Const. de Garantia de Direitos (ITE) \\ Universidade Estadual do Mato Grosso do Sul (UEMS) \\ Naviraí, Mato Grosso do Sul, Brasil \\ E-mail: manuella@uems.br
}

\begin{abstract}
Resumo: A dignidade humana deve ser encarada como sendo uma qualidade inerente a todo e qualquer ser humano e não apenas um direito específico da existência humana, como o direito à propriedade, à vida, à saúde etc. Assim, a dignidade humana é consequentemente o núcleo efetivo dos direitos; é a fonte jurídico-positiva dos direitos fundamentais, além de ser considerada o nascedouro da ética que atribui sentido à vida. No caso das pessoas com deficiência, a efetivação da dignidade da pessoa humana está atrelada a diversos fatores, dentre deles o fato da pessoa conseguir se inserir no mercado de trabalho, já que tal circunstância indubitavelmente contribui para a melhora e o desenvolvimento da autoestima e da confiança dessas pessoas. Todavia, percebe-se que apesar de existirem diversas leis que garantem essa inclusão no mercado de trabalho, a efetividade delas é bastante baixa, o que precisa ser otimizado. Nesse viés, o presente artigo, que é parte da tese de doutorado "A Ação Civil Pública como instrumento catalisador da inclusão das pessoas com deficiência no mercado de trabalho nas hipóteses não abrangidas pela Lei de Cotas", apresentada no Centro Universitário de Bauru (2017), pretende apresentar soluções para essa vicissitude, por meio de uma pesquisa qualitativa, de cunho exploratório, pautada em análise bibliográfica.
\end{abstract}

Palavras-chave: Dignidade da pessoa humana. Pessoa com deficiência. Inclusão. Mercado de trabalho. Mercosul.

Resumen: La dignidad humana debe verse como una cualidad inherente a todos y cada uno de los seres humanos y no solo como un derecho específico de la existencia humana, como el derecho a la propiedad, la vida, la salud, etc. Por lo tanto, la dignidad humana es, por lo tanto, el núcleo efectivo de los derechos; Es la fuente legalmente positiva de los derechos fundamentales, además de ser considerada la cuna de la ética que da sentido a la vida. En el caso de las personas con discapacidad, la realización de la dignidad de la persona humana está vinculada a varios factores, entre ellos el hecho de que la persona puede ingresar al mercado laboral, ya que tal circunstancia sin duda contribuye a la mejora y el desarrollo de la autoestima y La confianza de estas personas. Sin embargo, está claro que aunque existen varias leyes que garantizan esta inclusión en el mercado laboral, su efectividad es bastante baja, lo que debe optimizarse. En este sesgo, el presente artículo, que forma parte de la tesis doctoral "Acción civil pública como catalizador para la inclusión de personas con discapacidad en el mercado laboral en casos no cubiertos por la Ley de Cuotas", presentado en el Centro Universitario de Bauru (2017), tiene la intención de presentar soluciones para esta vicisitud, a través de una investigación cualitativa, de naturaleza exploratoria, basada en el análisis bibliográfico.

Palabras clave: Dignidad de la persona humana. Persona con discapacidad. La inclusión. Mercado de trabajo. Mercosur. 


\section{Introdução}

A preocupação com a proteção e a inclusão das pessoas com deficiência, e a concretização dos seus direitos fundamentais, se apresenta como questão inesgotável de discussão em todo o mundo, não sendo diferente nos países que formam o Mercosul. Foi sob essa ótica que há algum tempo resolveu-se dedicar um pouco mais de espaço e de atenção à problemática envolvendo os direitos atinentes a inclusão das pessoas com deficiência no mercado de trabalho, uma vez que indubitavelmente o trabalho contribui para a melhora e o desenvolvimento da autoestima e da confiança de todos.

Nessa senda, é necessário que as empresas reconheçam a necessidade da inserção dessas pessoas no mercado de trabalho, oferecendo-Ihes mais oportunidade para que possam conquistar seu espaço, a fim de que a empregabilidade seja garantida e mantida, contribuindo para o progresso social democrático.

No tocante aos países que fazem parte do Mercosul, é importante ressaltar que a dificuldade de inclusão não repousa na inexistência de normatização específica, já que há legislação inclusiva em todos eles, as quais fazem previsão do ingresso da pessoa com deficiência no mercado de trabalho. A dificuldade está assentada na falta de vontade política e no desinteresse da classe empresária em efetivar essa inclusão.

Dentro dessa perspectiva, é que o presente trabalho, resultado de parte da pesquisa realizada para a tese de doutorado "A Ação Civil Pública como instrumento catalisador da inclusão das pessoas com deficiência no mercado de trabalho nas hipóteses não abrangidas pela Lei de Cotas", apresentada no Centro Universitário de Bauru (2017), pretende apresentar soluções para a efetivação do direito de inclusão das pessoas com deficiência dos países do Mercosul no mercado de trabalho, por meio de uma pesquisa qualitativa, de cunho exploratório, pautada em análise bibliográfica.

\section{Pessoa com deficiência, direitos humanos e direito do trabalho}

Os direitos das pessoas com deficiência estão atrelados com a evolução da conquista dos direitos humanos, tendo em vista que à medida que o direito à igualdade de oportunidade, a justiça distributiva e a própria dignidade da pessoa humana passaram a ser objeto de estudo, os direitos das pessoas com deficiência também evoluíram.

Gradativamente houve uma mudança com relação à inclusão das pessoas com deficiência com enfoque na solidariedade e no acolhimento, que até pouco tempo eram estigmatizadas e à margem dos grupos sociais. O progresso e a valorização da pessoa humana, como um lado da dignidade humana, traduzem-se na efetividade do direito ao trabalho, uma vez que este acaba por incluir a pessoa na sociedade, deflagrando sentimento de igualdade.

Assim, o trabalho é um valor muito importante às pessoas com deficiência, já que possibilita a independência financeira e, por consequência, a autonomia. Araujo (2017) ao tratar do tema, ensina que "a proteção, em nosso caso, das pessoas portadoras de deficiência, nada mais é do que uma forma de proteger a cidadania e a dignidade da pessoa humana, eliminando as desigualdades sociais". 
O reconhecimento da vulnerabilidade dessas pessoas é inegável. Os limites de autodeterminação e liberdade pessoal são ponderados em vista à proteção da dignidade e integridade do deficiente. A pessoa com deficiência passa a ter uma dignidade efetiva quando elidida a exposição ao preconceito, já que adota novos comportamentos, fazendo com que a sociedade passe a respeitá-la mais.

Além disso, é incontroverso que as pessoas com deficiência que trabalham têm sentimentos de alegria, felicidade e bem-estar, tanto no aspecto social como no profissional, já que o bem-estar no trabalho relacionase ao sentimento da valorização humana depositada na relação jurídico-laboral que reduz o estigma social de incapacidade de tais pessoas (CARVALHO, 2007).

Nesse sentido, leciona Sassaki (1997) que o trabalho indubitavelmente contribui para a melhora e o desenvolvimento da autoestima e da confiança das pessoas com deficiência. Seu papel é o de proporcionar aprendizagem, crescimento, transformação de conceitos e atitudes, aprimoramento e remuneração. É necessário, portanto, que as empresas reconheçam a necessidade da inserção dessas pessoas no mercado de trabalho, oferecendo-Ihes oportunidade para que possam conquistar seu espaço no mercado, a fim de que a empregabilidade seja mantida, contribuindo para o progresso social democrático.

Destarte, a inclusão social pelo trabalho das pessoas com deficiência, além de garantir o direito à igualdade e à não discriminação, garante ainda a felicidade pessoal que, segundo Santo Tomás de Aquino, é o fim almejado de toda a sociedade (ROSTELATO, 2009).

[...] filósofos de todos os tempos colocaram a felicidade como a aspiração dominante do ser humano, que a procura cada qual a sua maneira. A felicidade, sendo a grande referencia à vida, é, nesse sentido, a motivação maior ao trabalho, direcionando passos, caminhos, relacionamentos e metas. O homem-pensamento, o homem-emoção e o homem-ação ganham integridade no ser feliz [...] (MATOS, 1997, p. 7).

Dessa maneira, é incumbência do Estado promover a inclusão das pessoas com deficiência, a fim de torná-las e mantê-las felizes, como prova de assegurar-lhes a dignidade humana. Nesse contexto, Rulli Neto defende que:

[...] a formação da ideia de Estado moderno agrega a felicidade como um dos objetivos a serem alcançados, dentro da afirmação da dignidade eminente da pessoa humana e na liberdade consistente na possibilidade de coordenação consciente dos meios necessários à realização da felicidade pessoal (RULLI NETO, 2002, p. 65).

Portanto, é possível afirmar que a dignidade humana está intimamente relacionada ao anseio da felicidade como ser humano no exercício de suas funções. A felicidade deve ser encarada como um objetivo atingível, uma finalidade (ALARCÓN, 2004). Desse modo, tem-se que a dignidade humana não é propriamente uma criação constitucional de cada país, mas é um valor supremo a todas as constituições. Na expressão escorreita de Barroso (2019), a dignidade da pessoa humana assume dimensão transcendental e normativa, e a Constituição passa a ser não somente "o documento maior do direito público, mas o centro de todo o sistema jurídico, irradiando seus valores e conferindo-Ihe unidade".

Nestes termos, garantir a inclusão da pessoa com deficiência no mercado de trabalho é assegurar efetivamente a dignidade dessas pessoas. A inclusão deve consolidar uma mudança de paradigma, em que as 
pessoas com deficiência vão parar de serem vistas como 'objetos' de caridade, tratamento médico e proteção social; mas passarão a ser vistas e tratadas como 'sujeitos de direitos', iguais a quaisquer outros indivíduos.

A sociedade deve ser inclusiva e, como tal, deve tratar a pessoa com deficiência como um cidadão hábil, valorizando suas qualidades profissionais. Desse modo, para a inserção dessas pessoas na sociedade, há a necessidade de a sociedade buscar conhecimento e informação a respeito das limitações e da capacidade delas. Há necessidade da sociedade eliminar todo tipo de barreira que impede a efetiva inclusão, em especial as sociais, como defende Neri:

[...] alguns dos principiais problemas das pessoas com deficiência têm origem na sociedade, ou seja, decorrem de barreiras sociais e não barreiras funcionais decorrentes da sua limitação, por exemplo: uma pessoa paraplégica estaria impedida de frequentar as aulas em uma escola onde não existe rampa e nem pessoas aptas a ajudá-la com transporte no trajeto casa-escola-casa. A partir da remoção dessas barreiras sociais (criações de condições arquitetônicas, de transporte e um pouco de solidariedade ou apoio familiar) essa pessoa passaria a exercer atividades escolares normais, ou seja, mediante algumas acomodações, a pessoa portadora de deficiência sairia da categoria de desvantagens em relação às demais (NERI, 2003, p. 3).

Toda a sociedade deve importar-se com a efetivação da inclusão. Deve haver vontade política para a construção de uma prática social menos preconceituosa e discriminante, fundando-se em um processo de construção de consenso de valores, políticas e princípios, proveniente de uma reflexão coletiva sobre o que realmente traduz a deficiência.

Somente aceitar as diferenças não é suficiente. Há necessidade de agir, de fazer com que os considerados 'diferentes' sejam incluídos na sociedade, sejam tratados de maneira igual. Mia Couto (2011) fala muito bem a respeito das diferenças, demonstrando o quão importante é aceitá-las e lutar pela efetiva inclusão. O autor defende que há necessidade de se colocar no lugar do outro, para entender e apoiar os 'diferentes', embora o escritor português admita que tal processo não seja fácil:

Difícil é sermos os outros. Nem que seja por um instante, nem que seja de visita. (...) Dizemos que somos tolerantes com as diferenças. Mas ser-se tolerante é ainda insuficiente. É preciso aceitar que a maior parte das diferenças foi inventada e que o Outro (o outro sexo, a outra raça, a outra etnia) existe sempre dentro de nós (COUTO, 2011, p. 135).

A verdade é que o ser humano se faz humano quando não se diferencia. A ideia de que a pessoa se faz pessoa a partir de padrões sociais convencionados é repugnante. A própria existência humana deve evidenciar a inclusão, abarcando todos os membros da sociedade, fomentando uma convivência harmônica amparada na diversidade, considerando o valor humano como primordial. Habermas (2004), contextualizando a questão da inclusão de minorias vulneráveis, disserta que:

O mesmo respeito para todos e cada um não se estende àqueles que são congêneres, mas à pessoa do outro ou dos outros em sua alteridade. A responsabilização solidária pelo outro como um dos nossos se refere ao "nós" flexível numa comunidade que reside a tudo o que é substancial e que amplia constantemente suas fronteiras porosas. Essa comunidade moral se constitui exclusivamente pela ideia negativa da abolição da discriminação e do sofrimento, assim como da inclusão dos marginalizados - e de cada marginalizado em particular - , em uma relação de deficiência mútua. Essa comunidade projetada de modo construtivo não é um coletivo que obriga seus membros uniformizados à afirmação da índole própria de cada um. Inclusão não significa aqui confinamento dentro do próprio e fechamento diante do alheio. Antes, a "inclusão do outro" significa que as fronteiras da comunidade estão abertas a todos - também e justamente àqueles que são estranhos um ao outro - e querem continuar sendo estranhos (HABERMANS, 2004, p. 7-8). 
Portanto, a diversidade implica que as particularidades de cada um mereçam total e irrestrito respeito na convivência social, de modo que seja observado a todos o pleno desfrute do direito à vida social. Diante de tal importância é que a edificação dos direitos humanos é uma preocupação mundial. Dentro do anseio de efetivação e respeito a esses direitos, encontra-se a proteção às pessoas com deficiência. Há uma luta globalizada contra a discriminação e a favor da inclusão dessas pessoas em todos os setores da sociedade.

Além disso, há uma preocupação muito grande de garantir às pessoas com deficiência o direito fundamental ao trabalho. Aliás, antes de abordar a questão da inclusão das pessoas com deficiência como forma de garantir a dignidade humana delas e seu direito fundamental ao trabalho, é importante tecer algumas considerações. Nesse sentido:

O direito ao trabalho é uma garantia de todos os indivíduos onde se compreende o direito à própria subsistência e o exercício da dignidade humana. As pessoas portadoras de deficiência também têm esse direito, este trabalho pode-se desenvolver em ambientes protegidos ou comuns e abertos a outros indivíduos. Para isso é preciso ter condições de transporte, tendo em vista que os portadores de deficiência tenham maior dificuldade de locomoção. A dignidade da pessoa humana e a integração social não serão plenamente atingidas se existir privação de direito ao trabalho e ao transporte adequados de acordo com as necessidades especiais (LUNARDI, 2003, p. 478).

Tecidas essas observações, cabe tratar a inclusão no contexto internacional das pessoas com deficiência não só na sociedade, de maneira geral, mas especialmente no mercado de trabalho. Após a Segunda Guerra Mundial, por conta das atrocidades realizadas pelos nazistas justificadas pela suposta supremacia da raça ariana, a preocupação com as minorias aumentou.

O problema passou a ser encarado também sob a óptica humanitária, e não apenas do aspecto político. Nesse cenário é que a atenção às pessoas com deficiência aumentou, até porque, após duas grandes guerras mundiais, o número de pessoas com deficiência de locomoção, audição, visão, etc, cresceu sobremaneira. Muitos foram os diplomas legais que surgiram nessa época com a finalidade de efetivação da dignidade da pessoa humana, extermínio das formas de discriminação e garantia de inclusão das minorias.

\section{Os tratados internacionais a respeito das pessoas com deficiência}

O primeiro grande documento internacional que veda qualquer tipo de discriminação é a Carta das Nações Unidas, promulgada em 26 de junho de 1945. Como já abordado, após o fim da Segunda Guerra Mundial, entre os líderes mundiais criou-se um sentimento de união entre as nações para que fossem prevenidas novas guerras, no intuito de que a paz mundial fosse garantida em conjunto com os direitos humanos e o progresso social. Nesse cenário foi criada a ONU, por intermédio da Carta das Nações Unidas, ratificada pelo Brasil em 24 de outubro de 1945.

Pouco mais tarde, em 1948, a Assembleia Geral das Nações Unidas aprovou a Declaração Universal dos Direitos Humanos, pela Resolução № 217, por 48 votos a zero. Esse diploma não possui nenhum valor em relação a sua obrigatoriedade pelos Estados, apenas valor moral (LIMA, 2006). Todavia, por sua importância, 
deve ser encarada como uma fonte de máxima hierarquia no mundo do direito, pois consagra princípios fundamentais que devem nortear toda a civilização contemporânea (SUSSEKIND, 2000).

Essa Declaração é de suma importância para o presente estudo porque, embora não faça referência expressa alguma às pessoas com deficiência, consigna em seu art. 1ㅇ que todos os homens nascem livres e iguais em dignidade e direitos, sendo que o inciso XXIII do mesmo artigo assegura o direito ao trabalho, à livre escolha de emprego, a condições justas e favoráveis de trabalho e à proteção contra o desemprego.

Assim como garante que todos têm direito a um emprego, o art. $7^{\circ}$ proíbe qualquer tipo de discriminação, proclamando a igualdade entre os homens. Esse documento tem característica universal, garantindo a todas as pessoas os direitos fundamentais. Embora somente essa Declaração fosse capaz de proteger e garantir a dignidade da pessoa humana de todos os cidadãos, a ONU, em 1947, começou a aprovar vários outros documentos com uma tendência de proteger alguns grupos específicos que exigiam uma atenção particular, com normas mais pormenorizadas.

No âmbito da ONU, juntamente com a Declaração Universal dos Direitos Humanos, atualmente existem oito convenções internacionais reputadas como essenciais, por sua ampla e constante aplicabilidade, que compõem o cerne do sistema jurídico-normativo internacional dos direitos fundamentais do ser humano. São elas: 1) O Pacto Internacional dos Direitos Econômicos, Sociais e Culturais; 2) O Pacto Internacional dos Direitos Civis e Políticos; 3) A Convenção Internacional sobre a Eliminação de todas as Formas de Discriminação Racial; 4) a Convenção sobre a Eliminação de Todas as formas de Discriminação contra a mulher; 5) a Convenção contra Tortura e outros tratamentos ou penas cruéis, desumanos e degradantes; 6) A Convenção sobre os Direitos da Criança; 7) a Convenção Internacional sobre a Proteção dos Direitos de todos os Trabalhadores Migrantes e Membros de suas famílias e 8) a Convenção Internacional sobre os Direitos das Pessoas com Deficiência (LARAIA, 2009).

Como nesse estudo o enfoque é a pessoa com deficiência e sua inclusão no mercado de trabalho, de todas as convenções, inicialmente a mais importante é a Declaração dos Direitos das Pessoas Portadoras de Deficiência, promulgada pela ONU em 1975. Insta mencionar que antes a ONU promulgou, em 1971, declaração específica sobre os direitos do deficiente mental, assegurando a esse grupo o direito de gozar dos mesmos direitos assegurados às pessoas que não possuíam deficiência intelectual, a fim de que pudesse desenvolver ao máximo suas aptidões e possibilidades.

Tal Declaração não tratou especificamente em artigo algum o trabalho do deficiente mental, mas garantiu o direito a exercerem uma atividade produtiva ou alguma ocupação útil ${ }^{1}$. A Declaração dos Direitos das Pessoas Portadoras de Deficiência, de 9 de dezembro de 1975, foi muito mais abrangente, chegando a conceituar pessoa deficiente como "qualquer pessoa incapaz de assegurar por si mesma, total ou parcialmente, as necessidades de uma vida individual ou social normal, em decorrência de uma deficiência, congênita ou não, sem suas capacidades físicas ou mentais" (art. $\left.1^{\circ}\right)$.

${ }^{1}$ Art. $3^{\circ}$ da Declaração de Direitos do Deficiente Mental, de 20 de dezembro de 1971: O deficiente mental tem direito à segurança econômica e a um nível de vida condigno. Tem direito, na medida de suas possibilidades, a exercer uma atividade produtiva ou alguma outra ocupação útil. 
Essa declaração acabou por garantir, em treze artigos, a dignidade humana das pessoas com deficiência, assegurando-Ihes os mesmos direitos fundamentais que as pessoas não deficientes possuem, a fim de que pudessem desfrutar uma vida decente, normal e plena quanto possível.

Além desses documentos de caráter geral e de grande abrangência no cenário mundial, há outros que são aplicados apenas em determinadas regiões. Por exemplo, o sistema interamericano conta com vários instrumentos de proteção, como a Convenção Americana dos Direitos Humanos, a Carta Internacional de Garantias Sociais, a Carta de Organização dos Estados Americanos, a Convenção Interamericana para a Eliminação de todas as Formas de Discriminação contra as Pessoas Portadoras de Deficiência (Convenção da Guatemala), a Declaração Sociolaboral do Mercosul, entre outras (LARAIA, 2009).

Também é possível falar da Declaração de Washington de 1999, da Declaração de Madrid de 2002 e da Declaração de Sapporo de 2003, denotando, assim, a conscientização na sociedade internacional da importância da inclusão desse grupo (MAZZUOLI, 2019).

Dentre esses documentos, destacam-se alguns: a Carta Internacional Americana de Garantias Sociais, de 1948, aduz que o trabalho igual sempre deve corresponder a igual remuneração, independentemente de sexo, raça, credo ou nacionalidade do trabalhador (art. $2^{\circ}$ ).

No mesmo sentido, recriminando todo e qualquer tipo de discriminação, a Convenção Americana dos Direitos Humanos (Pacto de São José da Costa Rica), de 1969, tem como princípio básico a não discriminação, estabelecendo a igualdade como base em todos os seus sentidos.

A Declaração Sociolaboral do Mercosul, sancionada em 1998, também consagra a não discriminação como princípio, garantindo a igualdade efetiva de direitos, tratamento e oportunidade no emprego e ocupação.

O Tratado de Marraqueche para facilitar o acesso à obras públicas às pessoas cegas, com deficiência visual ou com outras dificuldades para ter acesso ao texto impresso de 2013 também teve uma grande influência na proteção das pessoas com deficiência.

Esse Tratado foi celebrado por iniciativa do Brasil, Paraguai, Equador, Argentina e México, conhecido como o "Tratado do Livro Acessível", em vigor desde 30 de setembro de 2016, nos termos do seu artigo 18.

É um tratado internacional emblemático no âmbito do regime multilateral da propriedade intelectual, por ser o primeiro tratado até então concluído que limita os direitos de propriedade intelectual de autores e editores, excepcionando o regime geral dos direitos dos autorais (regime de copyright) em prol da facilitação do acesso à leitura de obras impressas às pessoas cegas ou com deficiência visual.

No campo específico do trabalho, plano internacional, desde a sua fundação, em 1919, a OIT também editou normas que representam aspectos de dignidade do trabalhador e, portanto, se relacionam com direitos humanos. A proteção ao trabalhador, tratada como direitos humanos, esteve presente em outras esferas mundiais e no interior dos Estados.

Fixar direitos humanos no trabalho significa para a OIT harmonizar e explicitar os limites do trabalho decente no mundo. Os direitos dos trabalhadores da OIT, de 1919 até a Declaração da Filadélfia, de 1944, 
revelam preocupações no sentido de que as normas internacionais do trabalho se tornassem direitos subjetivos, no interior dos Estados-membros.

Em um segundo momento, a partir de 1944, quando adotada a Declaração de Filadélfia e incentivadas políticas sociais sejam amplas, percebe-se uma inclinação pelos direitos humanos como princípios, sem que o aspecto de direitos subjetivos seja dispensado.

Quando a OIT deflagra a guerra contra a necessidade, em 1976, propondo o conceito de necessidades básicas, vem à tona a formulação da OIT da concepção de direitos humanos como necessidades. E, ao final, a concepção de direitos humanos como princípio, que sempre esteve presente na ação da OIT, é adotada nas suas declarações e mais enfaticamente redimensionada na Declaração da OIT, relativa aos princípios e direitos fundamentais no trabalho, de 18 de junho de 1998 (BARZOTTO, 2007).

Percebe-se, portanto, que desde o início do século passado, há uma grande preocupação mundial de inclusão das pessoas com deficiência na sociedade, o que inclui a inserção no mercado de trabalho, e a proteção do trabalhador, sob o olhar da dignidade da pessoa humana.

\section{A inclusão das pessoas com deficiência no mercado de trabalho nos países do Mercosul}

Como já abordado anteriormente, há uma grande preocupação mundial em relação à inclusão das pessoas com deficiência no mercado de trabalho, o que não podia ser diferente nos países que fazem parte do Mercosul, tanto que foi assinado a Declaração Sociolaboral do Mercosul, sancionada em 1998, consagrando a não discriminação como princípio, garantindo a igualdade efetiva de direitos, tratamento e oportunidade no emprego e ocupação, que foi a base de tudo.

Como já abordado, em 13 de dezembro de 2006, a Assembleia Geral da ONU aprovou a Convenção sobre os Direitos das Pessoas com Deficiência e seu protocolo facultativo, que entraram em vigor em 3 de maio de 2008. A Convenção foi fruto de trabalho e debate desde dezembro de 2001, quando o México propôs à Assembleia Geral que fosse estabelecido um comitê especial encarregado de preparar uma convenção internacional que protegesse e promovesse os direitos e a dignidade das pessoas com deficiência.

Antes disso, porém, os países da América Latina demonstraram um compromisso com os direitos das pessoas com deficiência, aprovando uma convenção própria sete anos antes que a ONU aprovasse a Convenção sobre os Direitos das Pessoas com Deficiência.

A Convenção Interamericana para Eliminação de todas as Formas de Discriminação em relação às pessoas com deficiência foi assinada em 7 de junho de 1999, na Cidade da Guatemala, entrando em vigor em 14 de setembro de 2001. Com a aprovação dessa convenção, o Sistema Interamericano de Direitos Humanos converteu-se no primeiro do mundo em adotar um tratado internacional dedicado especificamente aos direitos das pessoas com deficiência.

Nos países do Mercosul há uma preocupação com a inclusão das pessoas com deficiência e todos eles mantêm um sistema de cotas. Na Argentina, há um regime de cotas obrigatórias para inclusão das pessoas 
com deficiência, tanto para o Estado e seus organismos descentralizados ou autárquicos como para os entes públicos não estatais e os órgãos públicos da Cidade de Buenos Aires, que estão obrigados a preencher suas vagas com $4 \%$ de pessoas com deficiência.

Já no sistema privado, não há legislação especifica de cotas alguma, sendo garantido apenas às pessoas com deficiência os mesmos direitos e obrigações dos demais trabalhadores. Todavia, as oficinas protegidas $^{2}$ e as empresas que contratem pessoas portadoras de deficiência de grupos de trabalho protegidos ${ }^{3}$ têm como incentivo a redução de $50 \%$ no valor das contribuições sociais a cargo dos empregadores, no que se refere a essas contratações (LOPES, 2005).

Aqueles que prestam serviço dentro das oficinas protegidas ou pertençam ao grupo de trabalho protegido, com perda igual ou superior a $33 \%$ da capacidade laboral, estão sujeitos a relação de trabalho especial, pela qual, em regra, o contrato de trabalho deve ser feito por prazo indeterminado, por escrito, aceitando-se, excepcionalmente que seja por prazo determinado (LOPES, 2005).

O Paraguai além de ter assinado a Convenção Interamericana para Eliminação de Todas as Formas de Discriminação em Relação às Pessoas com Deficiência, prevê em sua Constituição, no art. 88, que não será admitido qualquer tipo de descriminação entre os trabalhadores por motivos étnicos, de sexo, religião, condição social e preferências políticas ou sindicais.

Além disso, preleciona que o trabalho das pessoas com limitações ou incapacidades físicas ou mentais será especialmente amparado. Há também a Lei no 2.479/2004, que prevê a obrigatoriedade de que $5 \%$ dos cargos nos serviços públicos sejam ocupados por pessoas com deficiência. Todavia, na esfera privada, não há lei de cotas alguma para ingresso de deficientes no mercado de trabalho (FRETES, et al, 2004).

No Paraguai, embora haja algumas previsões constitucionais a respeito das pessoas com deficiência e parca legislação infraconstitucional, ainda não há leis suficientes que assegurem a implantação de medidas de acessibilidade integral dos deficientes tanto à educação como ao mercado de trabalho.

Em dezembro de 1996, foi apresentada a primeira proposta de projeto de lei para a criação da Secretaria Nacional de Deficiência, formulada pelas organizações de pessoas com deficiência, cujo projeto chegou ao plenário da Câmara dos Deputados, mas foi arquivado. Em outubro de 2010, foi apresentada uma nova proposta, também na Câmara dos Deputados, que pretendia ampliar a legislação sobre os direitos das pessoas com deficiência. O projeto de lei original foi apresentado na Câmara e aprovado com algumas modificações.

O Código Laboral del Paraguay, Lei no 213/93, em seu art. 16, traz que é obrigação do Estado oferecer educação profissional e técnica aos trabalhadores, ao mesmo tempo que indica que a política econômica deve ser adequada para que se consiga manter um equilíbrio justo de oferta e demanda de mão de obra, dar emprego

\footnotetext{
2 São as empresas cuja estrutura é similar àquela adotada pelas demais empresas, resguardada a peculiaridade de que essas entidades participam regularmente das operações de mercado, mas têm a finalidade de assegurar um emprego remunerado e a prestação de serviço de adaptação laboral e social aos trabalhadores que necessitam.

${ }^{3}$ São aqueles que padeçam de uma alteração funcional permanente prolongada, física ou mental que em relação a sua idade e meio social implique em desvantagem considerável para sua integração social, familiar, educacional ou laboral (Lei nº 22.431/81).
} 
apropriado aos desempregados, aos deficientes físicos e psíquicos, idosos e veteranos de guerra. Na mesma Lei, o art. 229 trata da não discriminação salarial.

Além disso, o Paraguai também tem o projeto Empleo Joven, que apoia os jovens com deficiência, executado por meio de uma aliança de várias organizações civis que conhecem e trabalham no setor, sob a responsabilidade do Instituto de Proteção às Pessoas Excepcionais (Instituto de Protección a Personas Excepcionales - Inpro) e do Serviço Nacional de Promoção Profissional (ESCOBAR, 2010).

Todavia, na prática, as pessoas com deficiência no Paraguai também têm dificuldade de serem incluídas no mercado de trabalho, como ensinam Fretes et al::

No obstante la igualdad de contratación prevista tanto en la Constitución Nacional y el Código del Trabajo, en este terreno las personas en discapacidad se encuentran totalmente en política, y por ende del marco legal adecuado que proteja, estimule y desarrolle el trabajo de las personas en discapacidad, las deja fuera del mercado laboral. Las principales barreras son la falta de formación y capacitación de la personas en discapacidad, la falta de adecuación y adaptación de los puestos de trabajo, la inaccesibilidad de los medios de transporte y la falta de régimen legal reglamentario (FRETES et al., 2004, p. 171).

Ainda sobre o problema de emprego das pessoas com deficiência, Fretes et al. defendem:

De acuerdo a la disposición del artículo 78, inciso c y el artículo 79 del Código del Trabajo vigente, la discapacidad física o mental sobreviniente del trabajador es causal de terminación del contrato de trabajo, sin alguna del empleador, en lo cual el trabajador discapacitado y su familia quedan marginados en una situación de mayor necesidad. Existen algunas organizaciones que realizan acciones para ubicar a sus miembros en puestos públicos y privados. Sin embargo, estas acciones son aisladas e insuficientes, por lo que el índice de participación de las personas en discapacidad en el mercado de trabajo es prácticamente inexistente (FRETES et al., 2004, p. 171).

Portanto, é possível perceber que embora haja regulamentação em relação à inclusão dos deficientes no mercado de trabalho do Paraguai, tais direitos não conseguem garantir a integração social das pessoas com deficiência na sociedade.

No Uruguai, a Lei no 16.095 estabelece, em seu art. 42, que 4\% dos cargos vagos na esfera pública deverão ser preenchidos por pessoas com deficiência e, no art. 43, exige, para a concessão de bens ou serviços públicos a particulares, que estes contratem pessoas com deficiência, embora não haja porcentual algum estabelecido (MTE, 2007).

Por fim, no Brasil, há a Lei das Cotas tanto no setor público, como no privado. No setor público é assegurado à pessoa com deficiência o direito de inscrever-se em concurso público, em igualdade de condições com os demais candidatos, para provimento de cargo e emprego cujas atribuições sejam compatíveis com a deficiência de que é portador, sendo reservado no mínimo o percentual de $5 \%$ em face da classificação obtida, concorrendo em todas as vagas.

Os editais dos concursos devem informar o número de vagas existentes e o número de vagas destinadas às pessoas com deficiência, as atribuições e as tarefas essenciais dos cargos, a previsão de adaptação das provas, do curso de formação e do estágio probatório, conforme a deficiência do candidato, e a exigência de apresentação, no ato da inscrição, de laudo médico atestando a espécie e graus ou nível de deficiência. 
No setor privado há a obrigatoriedade de contratação de pessoas com deficiência nas empresas com mais de cem empregados, na proporção de 2 a $5 \%$ do número de postos de trabalhos existentes, sob pena de multa. Desse modo, percebe-se que a preocupação em efetivar os direitos das pessoas com deficiência no mercado de trabalho nos países do Mercosul é grande. Todavia, o que se constata na prática é que a efetivação desse Direito ainda está longe de ser concretizada.

\section{A inclusão efetiva das pessoas com deficiência no mercado de trabalho nos países do Mercosul}

Não há dúvida de que o direito ao trabalho das pessoas com deficiência evoluiu muito e atualmente há muito mais pessoas incluídas no mercado que anteriormente. Todavia, ainda há muito que se prosperar. Se for feita uma análise do número efetivo de pessoas com deficiência no mercado de trabalho, percebe-se que ainda é muito pequeno. Inúmeros são os fatores que impedem essa inclusão. As justificativas mais comuns apresentadas pelos empregadores são a baixa escolaridade das pessoas com deficiência e a falta de capacitação.

Na realidade, não é a falta de escolaridade que impede a contratação, mas outras barreiras, como o preconceito por parte do empregador, a falta de acessibilidade urbana, a falta de conhecimento a respeito das deficiências, entre outras. Diante desse cenário, não há dúvidas de que o problema da falta de vagas para inclusão de pessoas com deficiência no Mercosul deve ser resolvido o mais rápido possível.

O melhor caminho seria a eliminação, de modo geral, do preconceito pelos empregadores, a fim de que estes não oferecessem resistência em contratar pessoas com deficiência. Mas, infelizmente, essa realidade nesses países está longe de ser alcançada.

O ideal seria que a população se conscientizasse da necessidade premente de uma transformação paradigmática, afastando essa condição sócio histórica de marginalização e ressaltando a importância das políticas públicas para garantir essa inclusão. A melhor solução para o problema seria investir na educação da população, uma vez que somente por meio dela haverá construção de conhecimento para que se alcancem novos desafios para a presente e futuras gerações, provocando uma consciência efetiva nos empregadores, com a consequente diminuição do preconceito em relação a esses trabalhadores, resultando certamente no aumento de contratações de pessoas com deficiência.

A educação é o elo transformador entre as ações afirmativas do Estado e a mudança que se almeja na sociedade em relação à inclusão desses trabalhadores, fortalecendo os vínculos sociais para efetivação de direitos (NOGUEIRA; SOARES, 2015). Somente com a educação fortalecida é que se poderá efetivar a solidariedade e a igualdade entre os trabalhadores com e sem deficiência, libertando os deficientes da exclusão social. Há a necessidade de uma transformação social e da aceitação do outro; há a necessidade do reconhecimento ético do outro como igual (DUSSEL, 2000).

As pessoas devem se colocar no lugar de qualquer um, agir com solidariedade, independentemente da minoria que se quer defender. Há a necessidade de a sociedade tratar o trabalhador com deficiência com 
solidariedade, mas não a solidariedade como conceito antigo, próxima a um conceito de raiz religiosa, mas como conceito moderno. Nesse sentido, há a lição de Lucas:

La solidaridad de los modernos parte de la constatación de la diferencia, de la pluralidad, que no niega el vínculo social, sino que lo reformula (pluralidad social en lugar de uniformidad, homogeneidad), pero también de la desigualdad que obliga a pasar de la igualdad formal como equiparación a la igualdad formal como diferenciación y exige tratar desigualmente a los desiguales, para abocar a la igualdad material. De ahí arrancaría el mandato de esta otra solidaridad como principio jurídico (LUCAS, 2006, p. 159).

Nesses termos, a solidariedade moderna significa "assumir os interesses do outro como seus próprios interesses" (LUCAS, 2006), assumindo os interesses do grupo, atuando positivamente para a eficácia dos direitos, na medida em que se trata de uma responsabilidade de todos e de cada um.

Além do princípio da solidariedade, pode-se falar ainda no direito fraternal que, embora ainda não esteja consolidado como paradigma ou teoria, é uma forma de nova abordagem de análise do direito atual, a qual propõe uma reestruturação de todas as políticas públicas que pretendam uma inclusão universal.

De acordo com Horita, solidariedade não é sinônimo de fraternidade:

(...) fraternidade é o mesmo que investigar uma "igualdade de dignidade entre as pessoas, independente do modelo de organização em que vivem". Por outro lado, solidariedade implica em "uma comunhão de interesses, atitudes ou sentimentos por parte dos membros de um grupo, com o propósito de autodefesa ou resistir às investidas ou forças de agentes". Assim, há que se mencionar que a solidariedade distingue da fraternidade no quesito da possibilidade de admitir o fator desigualdade, permitindo que alguns indivíduos possuam mais direitos que outros (HORITA, 2013, p. 27).

A fraternidade deve ser vista como uma nova possibilidade de integração, como a igualdade de dignidade entre os seres humanos (RESTA, 2004), como a solução da inclusão das pessoas com deficiência no mercado de trabalho. O direito fraterno vem consolidar a liberdade e igualdade, direitos que embora inscritos em nossa Constituição, muitas vezes são esquecidos, já que em regra o que se dá é a exclusão e não o acesso.

Falar em direito fraterno é falar em dignidade da pessoa humana, porque o princípio da dignidade humana, como fundamento do Estado e garantidor da vida, é a garantia de um direito mais digno. Assim, a ordem jurídica, fundada no princípio da igualdade e da paz, voltada para a dignidade da pessoa humana, é o ordenamento da fraternidade (POZZOLI, 2001).

Assim, preocupar-se com a efetivação da dignidade humana nada mais é que falar de um direito fraterno. A ordem jurídica, fundada no princípio da igualdade e da paz, voltada para a dignidade da pessoa humana, é o ordenamento da fraternidade. A fraternidade deve ser encarada como uma necessidade para uma melhor convivência em sociedade. A Declaração Universal dos Direito Humanos é a prova da concretização do princípio da fraternidade. Sobre isso, Pozzoli ensina:

A referida declaração, objeto de um estudo mais específico no item seguinte, consigna no seu texto o reconhecimento da dignidade da pessoa humana inerente a todos os membros da família humana e de seus direito iguais e inalienáveis como constitutivos do fundamento da liberdade, da justiça e da paz. Foram elementos importantes que tornaram os direitos da pessoa humana protegidos, para que a pessoa não se veja levada ao supremo recurso da revolta contra a tirania e a opressão (POZZOLI, 2001, p. 110). 
Portanto, com base nesse princípio é que se pode exigir uma alteração legislativa com o objetivo de se efetivar a igualdade entre trabalhadores com e sem deficiência. É a garantia da igualdade real entre todas as pessoas que compõe a sociedade. A fraternidade deve ser encarada como uma oportunidade social, onde se garantirá reciprocidade na humanidade, direcionando o Direito para algo mais justo e digno.

Outra maneira de garantir a inclusão é a criação de leis e ações afirmativas para aceleração do processo. Esse foi o modo escolhido pelos países do Mercosul, quando foram publicadas as Leis de Cotas. Porém, apenas a Lei de Cotas no setor privado não vem sendo suficiente para garantir a inclusão desses empregados. Portanto, diante desse quadro crítico, percebe-se que, embora as Leis de Cotas tenham sido um avanço na efetivação da inclusão e da garantia de direitos fundamentais, ainda estão longe de atingir o objetivo pretendido. Há a necessidade de mudanças sérias e urgentes para chegar aos resultados ideais. A educação, solidariedade e fraternidade são ferramentas que podem ser a solução definitiva do problema da inclusão desse grupo de trabalhadores.

\section{Considerações finais}

A presente questão deve ser indiscutivelmente analisada sob a ótica das proteções e das garantias constitucionais vigentes, considerando-se que a pessoa com deficiência possui o indelével direito de participar da vida social e comunitária, sendo que uma das formas é o exercício de atividade laborativa de maneira digna e condizente a dignidade humana, existindo, por conseguinte, a obrigação estatal de prover todas as condições necessárias pertinentes a sua peculiar condição, sob pena de, em assim não agindo, estar-se tornando ainda mais gravosa a condenação anteriormente impingida, o que, sem sombra de dúvidas, estaria a violar também o princípio da igualdade.

Isso porque, o objeto de proteção perseguido pelos legisladores foi, e ainda é, o tratamento idêntico de todos pela legislação, de tal modo que a manutenção do descumprimento e da inobservância estatal em relação as condições especiais apresentadas pela pessoa com deficiência estarão a continuar perniciosa e odiosa atividade discriminatória e excludente não contemplada por nenhum dos ordenamentos do Mercosul.

Uma das grandes preocupações em relação a necessidade de efetivação da dignidade da pessoa humana e, consequentemente, da concretização do princípio da igualdade no seio social diz respeito às minorias e aos grupos vulneráveis, os quais, seja em razão de apresentarem comportamento diferenciado daquele normalmente experimentado por uma determinada comunidade, seja em razão de não ostentarem as mesmas características físicas e psíquicas verificadas na maioria dos indivíduos, sofrem os mais diversos tipos de discriminação e de e de exclusão, sendo, inclusive, expungidas injustamente do convívio social e do mercado de trabalho.

Nesse quadro, inegavelmente estão inseridas as pessoas com deficiência que diante de suas características peculiares estão a merecer precípua atenção protetiva e observadora das entidades estatais, a fim de que, realmente, seja concretizado o já mencionado princípio da igualdade. Por isso há necessidade de se falar em educação, solidariedade e fraternidade na efetivação dos direitos das pessoas com deficiência, já que apenas as Leis não estão sendo suficientes para garanti-lo. 
A educação provoca uma consciência efetiva nos empregadores, com a consequente diminuição do preconceito em relação a esses trabalhadores, podendo se afirmar que é o elo transformador entre as ações afirmativas do Estado e a mudança que se almeja na sociedade em relação à inclusão desses trabalhadores, fortalecendo os vínculos sociais para efetivação de direitos. A solidariedade também é importante porque a empatia transforma o mundo. As pessoas devem se colocar no lugar de qualquer um, assumir os interesses do outro como seus próprios interesses.

Por fim, a fraternidade também é uma forma de abordagem de análise do direito atual, a qual propõe uma reestruturação de todas as políticas públicas que pretendam uma inclusão universal, devendo ser vista como uma nova possibilidade de integração, como a igualdade de dignidade entre os seres humanos.

Falar em direito fraterno é falar em dignidade da pessoa humana, porque o princípio da dignidade humana, como fundamento do Estado e garantidor da vida, é a garantia de um direito mais digno. Assim, a ordem jurídica, fundada no princípio da igualdade e da paz, voltada para a dignidade da pessoa humana, é o ordenamento da fraternidade. Somente pensando assim é que poderemos garantir a efetiva inclusão dos trabalhadores com deficiência no mercado de trabalho de todos os países que compõe o Mercosul.

\section{Referências}

ALARCÓN, Pietro de Jesus Lora. Patrimonio genético humano e sua proteção na Constituição Federal de 1988. São Paulo: Método, 2004.

ARAUJO, Luiz Alberto David. A proteção constitucional das pessoas com deficiência. 4. ed. Brasília: Corde, 2017.

BARROSSO, Luiz Roberto. Curso de Direito Constitucional Contemporâneo. 8. ed. São Paulo: Saraiva, 2019.

BARZOTTO, Luciane Cardoso. Direitos humanos e trabalhadores. Atividade Normativa da OIT e os limites do Direito Internacional do Trabalho. Porto Alegre: Livraria do Advogado, 2007.

CARVALHO, Karina Mendes. Os desafios da inclusão da pessoa com deficiência no ambiente de trabalho. In: GUGEL, M. A.; COSTA FILHO, W. M.; RIBEIRO, L. L. G. (Orgs.). Deficiência no Brasil: Uma abordagem integral dos direitos das pessoas com deficiência. Florianópolis: Obra Jurídica, 2007.

COUTO, Mia. E se Obama fosse africano? São Paulo: Cia das Letras, 2011.

DUSSEL, Henrique. Ética da Libertação na idade da globalização e da exclusão. Petrópolis: Vozes, 2000.

ESCOBAR, Gabriel. Personas com discapacidad, VII informe sobre derechos humanos. Madrid: Trama editorial, 2010.

FRETES, Julio; PACHECO, Claudia.; ZACUR, A.; CODAS, Marta. Derechos humanos: utopía para las personas con discapacidad en Paraguai. CODEHUPY: Coordinadora de Derechos Humanos del Paraguay Editorial/Editor, 2004.

HABERMANS, Jürgen. A inclusão do outro: estudos de teoria política. $2^{\mathfrak{a}}$ ed., São Paulo: Edições Loyola, 2004.

HORITA, Fernando Henrique Silva. A fraternidade em debate: reflexos no ordenamento jurídico brasileiro.

Revista Thesis Juris, v. 2, n. 1, p 15-31, jan./jun. 2013. 
LARAIA, Maria Ivone Fortunato. A pessoa com deficiência e o direito do Trabalho. 2009. Dissertação (Mestrado em Direito das Relações Sociais) - Pontifícia Universidade Católica de São Paulo, São Paulo.

LIMA, Firmino Alves. Mecanismos antidiscriminatórios nas relações de trabalho. São Paulo: LTR, 2006.

LOPES, Glaucia Gomes Vergara. A inserção do portador de deficiência no mercado de trabalho: a efetividade das leis brasileiras. São Paulo: LTr, 2005.

LUCAS, Javier. Solidaridad y derechos humanos. In: TAMAYO, J. J. (Org.). 10 palabras clave sobre derechos humanos. Navarra: Verbo Divino, 2006.

LUNARDI, Soraya Regina Gaspareto. As incompatibilidades e incoerências da proteção constitucional da dignidade da pessoa humana e da lei de reserva de mercado para pessoas portadoras de deficiência. In. Luiz Alberto David Araujo (Coord.), Direito da pessoa portadora de deficiência: uma tarefa a ser completada. Bauru: EDITE, 2003.

MATOS, Francisco Gomes de. Fator QF- quociente de felicidade: ciclo de felicidade no Trabalho. São Paulo: Makron Books, 1997.

MAZZUOLI, Valerio de Oliveira. "Curso de Direitos Humanos." 6 ed. rev. atual. e ampl., Rio de Janeiro: Forense; São Paulo: Método, 2019.

MINISTÉRIO DO TRABALHO E EMPREGO. A inclusão das pessoas com deficiência no mercado de trabalho. 2‥ ed. Brasília, DF: SIT, 2007.

NERI, Marcelo. Retratos da deficiência no Brasil. Rio de Janeiro: FGV, 2003.

NOGUEIRA, André Murilo parente; SOARES, Manuella de Oliveira. Justificação democrática do princípio à duração razoável do processo, p. 308-328. Sistema Constitucional de Garantia de Direitos I / Vladimir Brega Filho; Flademir Jerônimo Belinati Martins \& Teófilo Marcelo de Arêa Leão Júnior,organizadores. - 1. ed. - Jacarezinho, PR: UENP \& Instituto Ratio Juris, 2015.

POZZOLI, Lafayette. Maritain e o direito 2001. São Paulo: Loyola, 2001.

RESTA, Eligio. O Direito Fraterno. Trad. Sandra Regina M. Vial. Santa Cruz do Sul: Edunisc, 2004.

ROSTELATO, Telma Aparecida. Portadores de Deficiência e Prestação Jurisdicional. Curitiba: Juruá, 2009.

RULLI NETO, Antonio. Direitos do portador de necessidades especiais. São Paulo: Fiuza, 2002.

SASSAKI, Romeu Kazuma, et al. Educação profissional e colocação no trabalho: uma nova proposta de trabalho junto à pessoa portadora de deficiência. Brasília: Federação Nacional das Apaes, 1997.

SUSSEKIND, A. Direito internacional do trabalho. 3. ed, São Paulo: LTr, 2000. 